\title{
PENSAMENTO AO QUADRADO: ROBERTO SCHWARZ E 0 BRASIL
}

\section{Fabio Mascaro Querido} é professor do Departamento de Sociologia da Universidade Estadual de Campinas (Unicamp). Campinas, SP, Brasil. E-mail: fquerido@unicamp.br Orcid: 0000-0003-1648-5615 http://dx.doi.org/10.1590/0102-235261/107

A serena flexibilidade do raciocínio do ensaísta obriga-o a uma intensidade maior que a do pensamento discursivo, porque o ensaio não procede cega e automaticamente como este, mas sim precisa a todo instante refletir sobre si mesmo.

Adorno (2003, P. 44)

\section{Da literatura à crítica social: o Brasil reinterpretado}

Com oito décadas de vida, completadas em 2018, Roberto Schwarz constitui sem dúvida um dos mais importantes intelectuais brasileiros em atividade. Sociólogo de formação e crítico por opção, Schwarz se destacou notadamente pela capacidade incomum de articular expressão literária e matéria brasileira, a análise imanente da primeira servindo como ângulo privilegiado - e até certo ponto inacessível às abordagens sociológicas e/ou econômicas - para a compreensão das nuances de uma formação nacional caracterizada pela convivência e combinação idiossincrática entre temporalidades históricas diversas, entre elementos "modernos" e "arcaicos". 
A opção pela crítica literária, assim como pela escrita ensaística, as quais lhe permitiram incorporar sob nova óptica os ensinamentos da sociologia produzida por seus professores na USP, em especial Fernando Henrique Cardoso, encontra-se na base da forma singular com que Schwarz interpelou a questão nacional, tomando-a não como horizonte "positivo" ancorado no "progresso" modernizador, e sim em chave "negativa", quer dizer, como um problema a ser decifrado. Através da análise de Machado de Assis e de outras expressões decisivas da cultura brasileira, o crítico descortinou, assim, por um prisma específico, algumas das feições decisivas dos impasses do processo de formação nacional, cujas "anomalias" constituem não o sinal do "atraso" a ser superado, mas sim da forma particular em que o "moderno" se impõe no país, no âmbito do desenvolvimento desigual e combinado do capitalismo global.

Se, por certo, as premissas sociológicas e metodológicas 236 de tal perspectiva podem ser encontradas na obra daqueles que inspiraram a sua reflexão - tais quais, além de Antonio Candido e dos autores oriundos do chamado "Seminário d'O Capital', os intelectuais da tradição "marxista-ocidental": Lukács, Benjamin, Brecht e, sobretudo, Adorno -, não menos verdadeiro é o fato de que Schwarz os alçou a um novo patamar crítico, na direção de uma (re)interpretação do Brasil que, embora tributária de avanços que a precedem, sobressai-se pela especificidade com que arremata a oposição à lógica da modernização como $a$ via para a superação do "atraso", oposição que ganhou em seus escritos mais recentes uma carga ainda mais "negativa", em consequência dos impasses vividos pela "modernidade à brasileira" contemporânea.

Nesse contexto, o objetivo deste artigo é analisar a obra (e a trajetória) de Roberto Schwarz do ponto de vista da sua abordagem, nas suas continuidades e descontinuidades, dos desafios e dos impasses do pensamento (e da ciência) social brasileiro, circunscrito que este estaria, mesmo nas suas vertentes 
mais avançadas, ao horizonte modernizador e industrializante à luz do qual foram pensadas as possíveis soluções ao problema da má-formação nacional. Parte-se da hipótese de que foi exatamente a transição precoce das ciências sociais para a crítica literária/cultural, sem renegar a primeira, mas sem ao mesmo tempo comungar do projeto de delimitação científica da sociologia levado a cabo naquele momento por Florestan Fernandes, que permitiu a Schwarz forjar um novo ângulo a partir do qual se tornou possível estabelecer uma visão singular - por sua carga "negativa", oriunda de uma incorporação ímpar do legado "frankfurtiano" - da sociedade brasileira, sociedade esta entrevista através da análise crítica da experiência intelectual e/ou artística da época.

Roberto Schwarz cumpriria assim, se a hipótese se confirma, na periferia do capitalismo, o programa adorniano de um pensar dialético, de um "pensamento ao quadrado", como diz Fredric Jameson (1985, p. 41), pensamento sobre o pensamento (ou sobre a cultura de modo geral) cujo objetivo é desdobrá-lo em chave histórica, tomando-o como indício mesmo quando distorcido - da objetividade social da época em questão. Entre Adorno e Machado de Assis, numa equação que atingiu o ápice em Um mestre na periferia do capitalismo, publicado em 1990, após o fim das esperanças abertas no início da década de 1980, a "dialética negativa" schwarziana se consolidou, então, ao seu modo, como uma contribuição singular - por certo polêmica e enredada num impasse não menos fulcral do que o por ele identificado nos seus objetos de crítica - ao pensamento social e às ciências sociais brasileiras, contribuição que, mais recentemente, se transmutou no esboço de um diagnóstico do capitalismo não apenas na periferia, senão também no centro do capitalismo.

\section{Das ciências sociais à crítica literária}

Nascido em Viena, em 1938, quando seus pais judeus e com posições políticas à esquerda - já estavam 
com passagens compradas para deixar o país em direção à Argentina, Roberto Schwarz faz parte da primeira geração de imigrantes que se beneficia da abertura e expansão (ainda que incipiente) do ensino superior brasileiro. Após passar por Budapeste, pela Iugoslávia, pela Itália e pela França, em seguida à anexação da Áustria pela Alemanha nazista, a família Schwarz chega ao Brasil - através de atestados falsos (cf. Blay, 2010, p. 479) - em 1940, instalando-se em São Paulo, cidade que receberia, entre 1926 e 1942, o afluxo de mais de 50 mil judeus oriundos sobretudo da Europa Central (cf. Rodrigues, 2011). Filho de pai advogado (Johan) e de mãe bióloga (Käthe), ambos de sólida formação cultural, o jovem Roberto optou, na segunda metade dos anos 1950 (estimulado por Anatol Rosenfeld, amigo da família e muito importante no seu processo de formação), pelo curso de Ciências Sociais na então Faculdade de Filosofia, Ciências e Letras da Universidade de São Paulo (FFCL-USP), na Rua Maria 238 Antônia, compartilhando, assim, a atmosfera em torno do que Antonio Candido chamou de "pensamento radical de classe média”, que se apresentara na Universidade desde os anos 1930 e 1940 (Candido, 2011, p. 5).

Na juventude, Schwarz vivenciou o auge do ciclo nacional-desenvolvimentista, caracterizado por uma relativa "hegemonia cultural da esquerda" que, mais tarde - conforme argumentou no conhecido artigo "Cultura e Política: 19641969”, redigido no exílio francês (1970) -, sobreviveria e até mesmo se intensificaria nos primeiros anos da ditadura militar, sendo defenestrada a partir do final de 1968, após a promulgação do AI-5. Retomada pela esquerda, no contexto da aposta nas virtudes potenciais da modernização, a questão nacional (na forma do "nacional-popular") se transformou, nesse período, no eixo das mais diferentes manifestações artísticas e/ou culturais, as quais, na sua diversidade, compuseram o que Marcelo Ridenti denominou "brasilidade revolucionária", verdadeira "estrutura de sentimento" 
(Raymond Williams) assentada a um só tempo na rememoração das "raízes populares nacionais" e na busca por uma via alternativa da modernização, "que, ao final do processo, poderia romper as fronteiras do capitalismo" (Ridenti, 2010, p. 89).

Como observa Ridenti, os expoentes desta estrutura de sentimento pertenciam, em grande medida, aos novos setores sociais que adentraram no campo intelectual, dentre os quais exatamente os descendentes de imigrantes como Schwarz. Ora, mesmo que tenha quase sempre abordado de modo crítico as esperanças (ou ilusões) associadas ao nacional-desenvolvimentismo e/ou ao nacional-popular, marcado que ficou pela derrota desta perspectiva em 1964, e até mesmo por isso, as marcas desse debate formativo estarão presentes, como termo comparativo ou como pano de fundo, em toda a reflexão intelectual posterior do crítico de origem austríaca.

Na FFCL-USP, em 1958, Schwarz foi convidado a participar do assim chamado "Seminário d' O Capital', ao lado de alguns outros poucos alunos, como Michael Löwy, Bento Prado Jr. e Paul Singer. Sem dúvida, a participação nos seminários quinzenais de leitura d'O Capital, organizados por professores como José Arthur Gianotti (filósofo), Fernando Novais (historiador) e os dois assistentes de Florestan Fernandes na cadeira de Sociologia I, Fernando Henrique Cardoso e Octavio Ianni, constitui um momento decisivo da formação do então jovem estudante Roberto Schwarz, situando-o desde cedo na órbita de certa tradição marxista-acadêmica (e sociológica) brasileira que, dali em diante, seria a matriz teórica de um conjunto de reflexões intelectuais críticas sobre o país - reflexões entre cujas razões "políticas" de ser se encontrava, como se sabe, a oposição ao ideário nacional-desenvolvimentista, seja em sua versão isebiana, cepalina ou mesmo "comunista".

Na mesma época, sentindo-se pouco atraído pela perspectiva de uma sociologia científica tal como arquitetada por Florestan Fernandes, Schwarz aproximou-se da figura 
de Antonio Candido, que havia acabado de migrar para a área de letras, e com quem já começara a colaborar, contribuindo com ensaios críticos para o suplemento literário do jornal O Estado de S. Paulo, dirigido pelo mestre. É Candido quem estimula Schwarz - que, em 1959, publicara pela editora Massao Ohno o livro de poesias Pássaro na Gaveta - a cursar o mestrado em teoria literária no exterior, após o qual ele poderia trabalhar como seu professor-assistente.

Almejando inicialmente estudar com Adorno na Alemanha, o jovem recém-formado em ciências sociais acabou indo para os Estados Unidos - em função das opções de bolsa de estudo - cursar o mestrado em literatura comparada na Universidade de Yale (um dos lócus do new-criticism), sob orientação de René Wellek, finalizando-o em 1963 (cf. Schwarz, 2009). De volta ao Brasil, além de animar uma nova versão, mais "politizada", do "Seminário Marx", a partir de 1963, ao lado de figuras como Ruy Fausto, Paul Singer, 240 Sergio Ferro, Emir Sader, João Quartim de Moraes, Emília Viotti, Francisco Weffort, dentre outros e outras, e de estar à frente da revista Teoria e Prática (que perdurou por apenas três números), em 1968, Schwarz lecionou teoria literária na USP até 1969, quando resolveu deixar o cargo e o país em função do recrudescimento da repressão, exilando-se, primeiro, no Uruguai e, depois, em Paris, onde cursaria o doutorado ao longo da primeira metade da década. Essa "passagem" da sociologia à crítica literária, sem voltar as costas à primeira, com a qual jamais deixaria de dialogar e nela se inspirar, constitui um momento decisivo na trajetória de Schwarz, uma vez que, entre outras coisas, redefiniu o campo de possibilidades intelectuais e acadêmicas no interior do qual ele se situaria.

Em conhecida conferência ("Crítica e sociologia - tentativa de esclarecimento”) proferida em julho de 1961 no II Congresso de Crítica e História Literária, realizado em Assis, do qual Schwarz participou, Antonio Candido - reatando com alguns de seus textos anteriores, como a tese de 
livre-docência de 1945, O método crítico de Sílvio Romero-delimitou as diferenças substantivas entre a "crítica sociológica" ou "sociologia da literatura" e o que ele entendia por "crítica", sem mais: enquanto a primeira se concentra e se contenta com a busca dos condicionantes sociais "externos" representados na obra literária, a segunda almeja visualizar na própria obra, mediante a "crítica imanente", os elementos histórico-sociais "formalizados" na estrutura literária, compreendendo-os "como fator da própria construção artística, estudado no nível explicativo e não ilustrativo". Assim sendo, "o externo se torna interno e a crítica deixa de ser sociológica, para ser apenas crítica” (Candido, 2000, p. 8).

Observa-se, assim, que o eixo dessa diferenciação teórica em relação à "crítica sociológica" residia, a bem dizer, na tentativa de Candido - seguida por Schwarz - de distinguir a sua "crítica integrativa" do tipo de sociologia produzida na USP de então, capitaneada por Florestan Fernandes, que havia assumido a direção da Cadeira de Sociologia I em 1954, após o retorno de Roger Bastide para a França, conferindo direção e coesão relativamente novas aos rumos da disciplina, em ruptura parcial tanto com a orientação precedente quanto com aquela da Cadeira de Sociologia II (da qual Candido fazia parte), a partir de então marginalizada (cf. Blanco e Jackson, 2014, p. 142-144). Daí, conforme bem observa Leopoldo Waizbort (2007, p. 113-114), a noção restrita de sociologia (identificada à versão "cientificista") com a qual operava Candido, tomando-a como parâmetro "negativo" de comparação, a fim de estabelecer as bases de sua própria concepção da "crítica" - concepção elevada a um novo patamar intelectual e "institucionalizada" com a criação da cadeira de Teoria Literária e Literatura Comparada na USP, a partir do início para os anos 1960, cadeira para a qual Schwarz foi o "primeiro elemento [professor assistente] recrutado" (Candido, 1974).

Em Schwarz, notadamente, a opção pela "crítica", entendendo-a na sua feição dialética, a meio-caminho 
entre ciência e estética, resultava da busca por outra forma de revelação da realidade social, interessada não apenas no ato cognitivo em si, senão também na maneira específica em que este é "comunicado", isto é, escrito, como o demonstraria sua redação repleta de "torções" dialéticas. Tal preocupação com a "forma" da escrita, razão de ser da verve ensaística que seria por ele adotada, naturalmente distanciava Schwarz do modelo científico apregoado por Florestan e seguido mesmo por seus brilhantes discípulos, a despeito da inflexão política e intelectual destes últimos a partir do final dos anos 1950.

Na ótica do jovem Schwarz, o jargão científico propagado por Florestan Fernandes impregnava a atividade intelectual não apenas do Departamento de Ciências Sociais da FFCL-USP ("exceção feita ao Antonio Candido, evidentemente"), mas também dos próprios membros do seminário (cf. Schwarz, 2009, p. 231). Haveria em ambos os casos (sociologia/seminário) 242 certa indiferença em relação ao "valor de conhecimento da arte moderna, incluída a brasileira" (Schwarz, 1999e, p. 104), algo que, conforme diria Schwarz décadas mais tarde, em mirada retrospectiva, acabou por limitar - por falta de "acabamento literário" - as "próprias intuições sociológicas" implícitas nos projetos intelectuais dos autores (Schwarz, 2009, p. 231).

Isso explicaria, para Schwarz, a inegável inferioridade dos trabalhos ali produzidos, enquanto obras (malgrado a maneira original de interpretar o Brasil que professavam), em relação aos "clássicos" do pensamento social e político brasileiro como Caio Prado Jr., Sérgio Buarque de Holanda ou Gilberto Freyre, ou seja, exatamente os ensaístas pré-institucionalização das ciências sociais com os quais Florestan almejava romper, a fim de estabelecer as condições para a profissionalização científica da disciplina - numa ruptura que se fazia tanto mais necessária em razão da continuidade temática entre as duas formas de pensar o país (cf. Ortiz, 1990, p. 166). 


\section{Entre a forma e a formação: a ideia em seu lugar}

Em sua trajetória intelectual, Schwarz buscou ele mesmo, ao que parece, escapar ao que via como impasses da original reflexão social sobre o Brasil gestada pelos partícipes do "seminário d'O Capital', imbuídos de um marxismo rigoroso e não-doutrinário. Em alguma medida, a transição para a crítica literária/cultural, a qual lhe permitia adotar o "ensaio como forma", significava para Schwarz uma maneira de superar os limites "sociologistas", por assim dizer, de Florestan e dos seus discípulos membros do "seminário d' $O$ Capital', elaborando - sob inspiração de Candido, mas com uma tonalidade particular, tingida pela reflexão estética/ cultural dos "marxistas ocidentais" - uma perspectiva singular por meio da qual repensou os ensinamentos da vertente marxista da "escola paulista de sociologia", especialmente os de Fernando Henrique Cardoso (cf. 1997). Ao mesmo tempo, cimentou um caminho por onde lograria, na contramão do "desprezo" acadêmico de seus mestres, tornar-se um dos mais finos observadores críticos das vitalidades e dos limites da arte e da cultura "modernas" no Brasil.

Desde seus primeiros trabalhos, reunidos no livro $A$ sereia e o desconfiado (1965), e com maior sofisticação nos ensaios redigidos a partir da virada para os anos 1970, Schwarz revelou a verve ensaística - própria de um "crítico", no sentido forte, da literatura e da cultura nacionais - que guiaria sua tentativa de articular na sua própria reflexão a inovação conteudística e conceitual dos seus colegas de seminário e o acabamento formal e/ou "literário" reputado como necessário para estar à altura do complexo desafio de se pensar as singularidades (e não as particularidades irredutíveis) de um país da periferia do sistema como o Brasil.

Realizado na primeira metade dos anos 1970, na Universidade Paris III, sob orientação de Raymond Cantel, o doutorado sobre Machado de Assis, ou, mais amplamente, sobre os percalços da dialética entre "forma literária" e 
"processo social" num país da periferia do capitalismo como o Brasil, significou o primeiro grande passo de Schwarz na consolidação de sua obra intelectual, em especial naquilo que a distingue do restante da "esquerda" intelectual da época. O primeiro ato deste processo foi a publicação - na França em 1972, na revista L'Homme et la Société, e no Brasil no ano seguinte, na revista do Centro Brasileiro de Análise e Planejamento (Cebrap) - do que seria a introdução da tese: o célebre texto "As ideias fora do lugar", no qual Schwarz analisa a "sensação" de desajuste entre aquilo que servia como "norma" a ser seguida pelas elites, a saber, o ideário liberal dominante no século XIX europeu, e o que, efetivamente, ocorria no "Brasil real", marcado pela escravidão e, também importante, pela "mediação quase universal do favor" entre os "homens livres", camada junto à qual, ao lado dos proprietários, gravitava a vida ideológica do país.

É deste desajuste de fundo, vinculado à simultânea ine244 vitabilidade "ideológica" e inviabilidade "prática" (nos seus preceitos básicos) do ideário liberal no país, que decorre, para Schwarz, a sensação de um "desacordo entre a representação e o que, pensando bem, sabemos ser o seu contexto" (Schwarz, 2000a, p. 25). Por aqui, nas palavras do autor, "adotávamos sofregamente os [argumentos] que a burguesia europeia tinha elaborado contra [o] arbítrio e [a] escravidão" (Schwarz, 2000a, p. 17). No Brasil oitocentista, as ideias e razões europeias "podiam servir e muitas vezes serviram de justificação, nominalmente 'objetiva', para o momento de arbítrio que é da natureza do favor. Sem prejuízo de existir, o antagonismo se desfaz em fumaça e os incompatíveis saem de mãos dadas" (Schwarz, 2000a, p. 18).

Já antes do golpe de 1964, Schwarz havia intuído a relação paradoxal entre a ironia machadiana e a realidade social brasileira no século XIX, com sua mistura de liberalismo e escravismo. Mas seria com a ditadura militar e sua modernização autoritária e conservadora que o "ceticismo 
machadiano" passaria "a ser entendido como acuidade histórica” (Schwarz, 1999c, p. 235), ao mesmo tempo que se revelava o caráter ilusório do arranjo positivador efetuado por Oswald de Andrade (e, décadas depois, pelos tropicalistas) entre o "moderno-de-província", o "moderníssimo" e o "arcaico", condensando-os numa "visão encantada do Brasil" (cf. Schwarz, 1987a), ilusões que, no Caetano Veloso dos anos 1990, se transformariam em apologia da desintegração contemporânea (cf. Schwarz, 2012b) ${ }^{1}$.

Na tese de doutorado, publicada em livro em 1977 com o conhecido título Ao vencedor as batatas, almejando estabelecer os nexos entre "forma literária" (romance) e "processo social” no país, Schwarz já estava, portanto, com a convicção de que existia uma relação com alto poder de revelação histórico-social entre o segundo Machado, o das Memórias Póstumas de Brás Cubas, e a "volubilidade" das elites pátrias, cuja alternância entre a norma e o arbítrio lhe garantia alta margem de manobra no trato com os "de baixo". Na feitura da tese, porém, a necessidade de investigar os "desajustes" que marcaram as tentativas anteriores de adaptação do romance à realidade do país, fez com que o trabalho, à diferença do previsto, se restringisse - além da introdução célebre - à análise de José de Alencar e dos primeiros romances de Machado (A mão e a luva, Helena e Iaiá Garcia).

Tanto é assim que a primeira edição do livro terminava com a seguinte inscrição: "continua", demarcando o caráter inacabado do trabalho, que apenas se completaria 13 anos depois, com a publicação de Um mestre na periferia do capitalismo, em que Schwarz analisa o ponto mais alto da "formalização" literária da nossa má-formação nacional. Em conjunto, como adverte o autor no prefácio do livro de 1990, ambos configuram um conjunto coerente e historicamente

\footnotetext{
1 Nos ensaios schwarzianos sobre aspectos da cultura brasileira a verve adorniana se faz presente no ceticismo diante dos arranjos afirmativos (e, nesse sentido, conformistas) da questão nacional. Cf. Schwarz, 1978 e 1987a.
} 
desenvolvido, cujo desfecho se dá numa "adequação" formal - promovida pelo Machado de Assis das Memórias... à altura da complexidade da matéria social brasileira do século XIX, figurando-a através da mimetização, por assim dizer, do movimento das elites nacionais.

Na interpretação de Schwarz, a "volubilidade" do narrador, "regra de composição da narrativa", estilizaria a "conduta própria à classe dominante brasileira", elevada à condição de "princípio formal", como diz o autor no "segundo" livro (Um mestre na periferia...). É isso o que explicaria os constantes vai-e-vem do narrador-defunto, formalizando a articulação bem brasileira entre o "moderno" e o "atrasado". Nas Memórias póstumas..., "o narrador não permanece igual a si mesmo por mais de um curto parágrafo, ou melhor, muda de assunto, opinião ou estilo quase que a cada frase". O narrador volúvel reproduz, assim, na sua forma, "implicações estruturais" do quadro histórico nacional pós-Indepen246 dência, tal qual ele se apresentava no movimento das classes dominantes brasileiras, a um só tempo liberais e escravistas.

Se tanto José de Alencar, com sua importação acrítica do modelo realista europeu, preenchendo-o com tipos locais, quanto o primeiro Machado, com sua racionalização e edificação do paternalismo, reiteraram, cada um ao seu modo, o desajuste entre modelo europeu e matéria local, caberia ao Machado da segunda fase transformar o deslocamento real em forma literária, vale dizer, em matéria artisticamente configurada, ainda que nem sempre de modo totalmente consciente. Antenado em relação às tendências literárias e filosóficas da atualidade europeia, assim como à prosa francesa e inglesa setecentista, Machado as retomou no contexto das relações sociais brasileiras, formando um quadro formal bem diferente daquele a que assistimos, por exemplo, no realismo tal qual teorizado por Lukács, que lhe serve como parâmetro comparativo (destituído, portanto, de sua carga normativa): o "realismo" machadiano decorre 
não da apresentação da "dinâmica de conjunto" que move as "tendências sociais", mas sim da própria dinâmica narrativa, fundada na preponderância do princípio formal (a volubilidade do narrador) como elemento mediador à figuração efetivamente "realista" do estatuto particular da sociedade brasileira pós-Independência.

Com a "escrita vertiginosa" de Brás Cubas, a qual destoa da fábula realista, o foco da mimese "se desloca do narrado para o ritmo específico do narrador" (Schwarz, 2000b, p. 203), revelando preocupações com a lógica própria do narrador "pós-realista" que remetem a Benjamin ("O narrador") e Adorno ("Posição do narrador no romance contemporâneo") mais do que a Lukács ("Narrar ou descrever"). Trata-se, segundo Schwarz, de uma "forma latente" (e não de uma "forma ostensiva"), na qual o "desequilíbrio" estético, se comparado ao cânone europeu, "trazia para o plano da forma uma tensão histórica existente" (Schwarz, 2000b, p. 191), fazendo com que as inconsistências sociais migrassem para dentro da obra literária. Em uma palavra, diz Schwarz: "o desajuste estrutural das Memórias reproduzia contradições objetivas” (2000b, p. 192), mesmo porque, como afirmou Adorno na sua Teoria Estética, "a parte subjetiva na obra de arte é em si mesma um fragmento de objetividade" (Adorno, 1982, p. 56).

No ambiente periférico, e posterior à virada europeia de 1848, Machado só conseguiu "escrever um romance realista" porque não hesitou em se aproveitar de "soluções literárias antirrealistas" (Schwarz, 2000b, p. 208), atinando com uma preocupação com a objetividade da forma em si que o colocava em linha com a literatura "pós-realista" e/ ou "pós-naturalista" europeia, profícua à estilização do feitio particular do nosso "eterno retorno do mesmo", figurada na compulsão do narrador machadiano à repetição, como se assim mimetizasse a feição "truncada" da modernização à brasileira (cf. Arantes, 1996, p. 135). 


\section{Dialética, dualismo e negatividade}

Em 1976, no que seria a primeira crítica à "tese" schwarziana das "ideias fora do lugar", Maria Sylvia de Carvalho Franco atribuiu ao crítico austríaco-brasileiro, sem mencioná-lo nominalmente, uma reposição do dualismo do qual acreditava estar a salvo. Para Franco, embora de maneira mais nuançada do que nas "teorias dualistas mais antigas", Schwarz (tanto quanto a "teoria da dependência") incorreria no mesmo equívoco de fundo, postulando uma relação de exterioridade entre as nações metropolitanas, tidas como centro produtor das relações socioeconômicas, e os países de extração colonial, periféricos e/ou subdesenvolvidos, que seriam seu produto. Neste tipo de interpretação, segundo a autora, observa-se uma tentativa de "combinação" de dois modos de produção diferentes, um dos quais determinando os rumos do outro.

Extrapolado para o mundo das ideias, essa lógica não poderia levar senão a uma concepção dualista, na qual, tal como na "nova teoria do pensamento brasileiro como ideias fora do lugar", seria possível identificar, "de um lado, as ideias e as razões burguesas europeias sofregamente adotadas para nada e, de outro, o favor e o escravismo brasileiros, incompatíveis com ela". Ao estabelecer tal tipo de oposição, acaba-se por "separar abstratamente os seus termos", perdendo-se de vista "os processos reais de produção ideológica no Brasil” (Franco, 1976, p. 61). ${ }^{2}$ Segundo Franco (1976, p. 63), retomando ideias outrora expostas na sua tese de livre-docência $O$ moderno e suas diferenças (Franco, 1970),

2 As críticas de Alfredo Bosi (2001) e, parcialmente, de Carlos Nelson Coutinho (2000) ao ensaio schwarziano coincidem, no geral, com a perspectiva de Carvalho Franco. Para todos eles, grosso modo, as ideias liberais no Brasil não estão "fora do lugar" e, por isso, não são uma farsa, acima de tudo porque são funcionais ao modo de realização da opressão capitalista no país. Para Schwarz, ao contrário, uma coisa não exclui a outra, e as ideias liberais podem ser funcionais e grotescas ao mesmo tempo, como se nota nos romances da maturidade de Machado de Assis. Sobre "Schwarz e seus críticos", ver Ricupero (2013). 
o nosso ideário liberal-burguês, como em qualquer outro lugar, "não entra no Brasil, seja lá como for, mas aparece no processo de constituição das relações de mercado, às quais é inerente". Por isso mesmo, a "miséria brasileira" não deve, para a autora, "ser procurada no empobrecimento de uma cultura importada e que aqui teria perdido os vínculos com a realidade", e sim no modo como "a produção teórica se encontra internamente ajustada à estrutura social e política do país" (Franco, 1976, p. 63).

Ora, não é difícil observar aqui certa incompreensão das sutilezas do argumento schwarziano, incompreensão induzida até certo ponto pelo título do ensaio, que parecia anunciar uma tese (o caráter irredutivelmente "fora do lugar" das ideias e/ou das formas europeias no Brasil) quando, na verdade, buscava expressar em termos teóricos uma sensação de desajuste realmente existente, "a sensação - como explica o próprio autor (Schwarz, 2012a, p. 166) - de que nossas ideias, em particular as adiantadas, não correspondem à realidade local”. O objetivo do ensaio não era, então, o de afirmar - na linha do pensamento conservador, "idealista orgânico" (cf. Brandão, 2007) - que as instituições e as ideias progressistas do Ocidente são estrangeiras e postiças no Brasil e em outros países de origem e situação semelhante, "mas sim [...] discutir as razões pelas quais parece que seja assim” (Schwarz, 2012a, p. 167), razões que decorreriam de relações hegemônicas no contexto das quais "o funcionamento europeu do liberalismo" se impôs, "decretando que os demais funcionamentos são despropositados" (Schwarz, 2012a, p. 170-171).

Para Schwarz, a raiz desse "mal-estar ideológico" encontra-se não nas ideias em si, mas na forma da inserção do país no circuito capitalista internacional após a "crise do antigo sistema colonial" (cf. Novais, 1983) e, depois, a Independência, inserção na qual o nosso "atraso" (também ele "moderno") é não apenas contemporâneo como 
funcional ao caráter "avançado" dos países hegemônicos. A diferença - entre nós e eles - não é, portanto, "um vestígio do passado, em vias de desaparecer, nem um acidente, mas um traço substantivo da atualidade periférica, com muito futuro pela frente" (Schwarz, 2012a, p. 169). Por isso mesmo, se a crítica de Franco a uma certa "positivação" do "capitalismo e seus conteúdos civilizatórios", bem como a uma "valorização tácita da industrialização", se aplica parcialmente à teoria da dependência, muito mais complicado é remetê-la à abordagem de Roberto Schwarz, cuja ênfase na dinâmica específica do mundo das ideias num país da periferia do sistema não significa uma recaída no dualismo entre atrasado e moderno, mas sim uma tentativa de articulá-los em torno da realidade concreta de um país que, se é capitalista, não o é exatamente da mesma forma que os países "metropolitanos".

Não se trata, portanto, ao menos não necessariamente, de qualquer espécie de "positivação" do progresso capitalista 250 e seu conteúdo civilizatório como horizonte a ser alcançado, entre outras coisas porque a crítica da situação dos países da periferia desmascara também, simultaneamente, a situação hegemônica dos países centrais, concorrendo para a crítica do sistema no seu conjunto, aqui como lá. Além disso, no caso de Schwarz, a importância do ceticismo machadiano no diagnóstico do Brasil redobra a dimensão "negativa" para a qual a questão nacional constitui antes um problema do que uma aspiração positiva. Em Machado, anota o crítico,

a especificidade nacional existia, mas tomava feição negativa, desde que fosse elaborada com verdade e de modo artisticamente satisfatório. Depois de ser um ideal, o "homem do seu tempo e do seu país" fazia figura de problema, quando não de vexame. (Schwarz, 1999a, p. 153)

O beco-sem-saída machadiano “atualiza”, então, em Schwarz, a "dialética negativa" à brasileira, dialética sem 
síntese, destituída da dimensão afirmativa presente, por exemplo, na teoria da dependência, sem falar nas concepções francamente dualistas.

Aqui a diferença fundamental entre Schwarz e seu mestre Antonio Candido: ainda que lhe seja uma mediação central na incorporação "à brasileira" dos autores europeus, Schwarz não compartilha, et pour cause, o "aspecto encantado" da esperança timidamente nacionalista revelada por exemplo pelo crítico no final do seu ensaio sobre a "dialética da malandragem", no qual a dialética ordem-desordem, se por um lado representava uma dimensão histórica, vinculada à "formalização estética de um ritmo mais geral da sociedade brasileira", por outro era esboçada como "ethos cultural", "modo de ser" (popular) brasileiro, cuja pouca interiorização da ordem poderia ser uma "vantagem brasileira" em relação ao primado dos valores puritanos, desde que sob condições favoráveis (Schwarz, 1987b, p. 150-152). Para Schwarz, escrevendo em 1979, tal "simpatia pelo universo que estuda" sinalizava o limite da análise dialética de Antonio Candido, obstruída por uma positividade "a-histórica" (o ethos "nacional"), positividade tanto mais problemática quando se tem em conta que a "extraordinária unificação do mundo contemporâneo sob a égide do capital" redefinira as saídas possíveis no concerto das nações (Schwarz, 1987b, p. 153).

Submetendo os ensinamentos adornianos à experiência social e intelectual brasileira, Schwarz lhes conferia potência explicativa, talvez mais ainda do que no centro do capitalismo, ao mesmo tempo que se resguardava - ao preço de certo isolamento (no que apenas satisfaria o mestre alemão) - de todo compromisso "positivo" com a necessidade de, via modernização e industrialização, contribuir para a completude da formação e integração nacional. Não é por acaso que, já nos anos 1990, agora também respaldado pelo diagnóstico de Robert Kurz (2011) sobre o "colapso da 
modernização" no segundo (União das Repúblicas Socialistas Soviéticas - URSS) e no terceiro mundos, Schwarz tenha apontado o desinteresse pela crítica de Marx ao fetichismo da mercadoria e, em consequência, pela crítica dos frankfurtianos ao "lado degradante da mercantilização e industrialização da cultura", assim como pelo valor de conhecimento da arte moderna, como os principais limites da experiência no mais exitosa do "Seminário d'O Capital' (Schwarz, 1999e, p. 104). Em correspondência ao ciclo nacional-desenvolvimentista, "o foco estava nos impasses da industrialização brasileira, que podiam até empurrar na direção de uma ruptura socialista, mas não levavam à crítica aprofundada da sociedade que o capitalismo criou e de que aqueles impasses faziam parte" (Schwarz, 1999e, p. 104).

Nesse contexto, a análise da lógica da mercadoria na "produção e normalização da barbárie pouco entrava em linha de conta e ficou como o bloco menos oportuno da 252 obra de Marx" (1999e, p. 104). Também para os "seminaristas", ainda que contribuíssem para a crítica às "ilusões de uma concepção linear do progresso", a questão decisiva era a superação "modernizadora" do atraso, para o que era necessário identificar os "obstáculos" (como diria Florestan Fernandes) à emergência de uma ordem social moderna no país, engajados que estavam em encontrar solução para o país, "pois o Brasil [tinha] que ter saída" (Schwarz, 1999e, p. 94, 104, grifos do autor). Se assim não fosse, eles teriam compreendido o subdesenvolvimento não apenas como consequência de relação subordinada aos países desenvolvidos, senão também como momento específico de um sistema global cuja lógica da mercadoria se encontra na base da "produção e normalização da barbárie" - tarefa que, se bem realizada, teria "alcance histórico-mundial, capaz de sustentar, suponhamos, algo como as Minima moralia referentes ao que é sem dúvida uma das feições-chave do destino contemporâneo" (Schwarz, 1999e, p. 104). 


\section{"Fim de século", fim de partida?}

A partir da virada para os anos 1990, mantendo a mesma hipótese sobre Machado de Assis como uma espécie de parâmetro heurístico para a análise das singularidades do processo de formação do país, Schwarz radicalizou a dimensão crítico-negativa do seu diagnóstico da modernidade à brasileira, num contexto marcado, a nível nacional, pelo desfecho conservador do processo de abertura democrática - desfecho confirmado com a derrota de Lula em 1989 -, e, no plano internacional, pelo refluxo da esquerda política e intelectual, duramente atingidas que foram, mesmo nas suas vertentes oposicionistas, pela desagregação do "socialismo" burocrático da URSS e dos países do leste europeu. Aposentado do Instituto de Estudos da Linguagem da Universidade Estadual de Campinas (Unicamp), onde lecionou de 1978 a 1992, mais uma vez por força da vontade de Candido, um dos criadores do IEL, Schwarz dedicou-se entre outras coisas, como se vê em pequenos ensaios da década, a fazer o balanço de um "fim de século" que se anunciava nebuloso. ${ }^{3}$

Foi este o título, aliás, "Fim de século", de uma comunicação apresentada por Schwarz na Universidade de Yale, em 1994, depois compilada em Sequências brasileiras (1999d), em que o crítico passa em revista a história recente do país a fim de demarcar o esgotamento de um ciclo (nacional-desenvolvimentista) que feneceu sem que as esperanças a ele vinculadas tenham se realizado, ao menos não na forma imaginada. Com a modernização e o desenvolvimento transformando-se

\footnotetext{
${ }^{3}$ Depois que voltou ao Brasil, em 1978, Schwarz teve papel importante, ainda que jamais formalizado, no âmbito do Cebrap, em particular na recriação da revista do centro, doravante denominada, a partir de 1981, Novos Estudos Cebrap. Schwarz foi o responsável pela redação do primeiro editorial da revista, intitulado "Amor sem uso", em que defende a necessidade de reavir o debate intelectual, aglutinando a reflexão crítica e, sobretudo, restabelecendo os seus vínculos com os movimentos populares, já que "a luta social [é] a única - não há nenhuma outra - chance de regeneração” (Schwarz, 1981, p. 3).
} 
em bandeiras do próprio regime militar - que, portanto, as realizava sem ruptura com o "atraso" e com o imperialismo e sem integração social, como esperavam os nacional-desenvolvimentistas -, a nova etapa que então se abria caracterizava-se, segundo Schwarz, acima de tudo, pelo impasse em relação a qualquer saída nacional possível para o país, como se o futuro já fosse o presente, encurtando de vez o nosso "horizonte de expectativas".

Nos anos 1980, finalmente, argumenta Schwarz, após os choques do petróleo, a crise da dívida e a nova ("terceira") revolução industrial que avançava a passos largos, "ficava claro que o nacionalismo desenvolvimentista se havia tornado uma ideia vazia, ou melhor, uma ideia para a qual não havia dinheiro" (1999d, p. 158). Não constitui um acaso, como se vê, a influência que "Fim de século" exercerá no argumento de fundo de "O ornitorrinco", provocativo e polêmico ensaio de Chico de Oliveira, publicado em 2003, 254 em que este bicho estranho, que não é isso nem aquilo, faz as vezes de alegoria do Brasil da passagem para o século XXI, o Brasil do desmanche e da exceção permanente que se tornou regra. ${ }^{4}$

Essa situação altera a relação entre países centrais e países periféricos, deslocando os termos em que se apresenta a problemática nacional, uma vez que, no limite, a desintegração em curso não constitui propriamente uma "questão nacional, e sim um aspecto da inviabilização global das industrializações retardatárias, ou seja, da impossibilidade crescente, para os países atrasados, de se incorporarem enquanto nações e de modo socialmente coeso ao progresso

\footnotetext{
${ }^{4}$ Na verdade, este e outros ensaios de Roberto Schwarz se tornaram referência não apenas para Chico de Oliveira (cf. Oliveira, 2007), senão também para o conjunto dos pesquisadores agrupados no Centro de Estudos dos Direitos da Cidadania (Cenedic-USP), como se vê no projeto coletivo financiado pela Fapesp, "Cidadania e democracia: o pensamento nas rupturas da política", vigente entre 2001 e 2005, coordenado por Maria Célia Paoli e subcoordenado por Laymert Garcia dos Santos (Unicamp) e pelo próprio Oliveira.
} 
e ao capitalismo" (Schwarz, 1999d, p. 160). A desintegração dos países "atrasados" sinaliza, assim, um momento de verdade do capitalismo contemporâneo como um todo, de tal modo que a tarefa não é a de simplesmente abandonar as "ilusões nacionais", na linha pós-estruturalista, mas sim a de submetê-las à crítica como expressão de um processo mais geral do qual nem mesmo os países "avançados" estão a salvo, razão pela qual estes já não mais se constituem em modelo a ser imitado. Por isso mesmo, um dos argumentos centrais de Schwarz a partir da virada para os anos 1990 é o de que a experiência periférica, exatamente por ser o lócus de um "desmanche" global, encontra-se agora em posição ainda mais privilegiada para abordar de modo crítico as desfuncionalidades das sociedades "pós-catástrofes" espalhadas tanto pelo Sul quanto, em menor intensidade, pelo Norte global (cf. Arantes, 2004).

A mediação nacional permanece, assim, embora historicamente deslocada, como um referente "negativo" inescapável, mesmo no ambiente aparentemente homogêneo decorrente da mundialização capitalista. É do problema nacional que emerge a vocação universal. Em ensaio de 2006, por exemplo, intitulado "Leituras em competição", no qual analisou os impactos da recente "canonização" internacional de Machado de Assis, Roberto Schwarz reafirmou a marca eminentemente nacional do escritor brasileiro, não para restringi-lo aos limites do país, mas sim para destacar a sua capacidade de, a partir da filiação a uma experiência local, constituir uma obra de grandeza "universal". "Foi no ambiente saturado de injustiças nacionais e de história que o achado universalista adquiriu a densidade e o impulso emancipatório indispensáveis a uma ideia forte de crítica" (Schwarz, 2006, p. 72). Ao contrário das leituras internacionais contemporâneas, para as quais Machado seria um "escritor plantado na tradição do Ocidente, e não em seu país" (2006, p. 67), como se no Brasil ele próprio fosse 
alguém "fora do lugar", Schwarz sustenta que um escritor como Machado só poderia existir, com a grandeza que lhe é peculiar, em um país da periferia do capitalismo como o Brasil - o mesmo se poderia dizer, mutatis mutandis, do próprio Roberto Schwarz (cf. Querido, 2013).

\section{Pensando ao quadrado: Roberto Schwarz e a teoria crítica à brasileira}

No legado machadiano, cuja abordagem da matéria local servia como "filtro" para a canalização do influxo externo, relativizando assim a própria condição de "norma" associada a este influxo, Schwarz encontrou, portanto, uma ancoragem pela qual se tornava possível "nacionalizar" a sua concepção do marxismo e das teorias críticas "universais" incorporadas. ${ }^{5}$ Ponto culminante do processo de "formação da literatura brasileira" analisado por Candido, em que enfim se produz uma síntese de tendências universalistas e particularistas, Machado proporcionou a Schwarz um ponto de apoio para a assimilação da teoria crítica a partir do princípio adorniano do primado do "objeto" sobre o método, no caso, do primado da matéria local articulada ao capitalismo global sobre as teorizações "universais" em voga.

Como diz Sérgio Miceli (2007, p. 55), "Roberto [Schwarz] reconfigurou o método frankfurtiano em algo tão seu a ponto de nunca precisar explicitá-lo à margem de sua prática intelectual - um feito invejável, em que raros se deram bem". Pois bem, isso apenas foi possível justamente porque a apropriação da herança frankfurtiana realizada por Schwarz se efetiva em torno do tratamento da experiência social e intelectual de um país da periferia

\footnotetext{
5 "Nacionalização" do marxismo no sentido empregado por Bernardo Ricupero (2000) em sua análise de Caio Prado Jr., ou seja, como teoria que se "funde" (e não meramente se aplica externamente) à realidade sob a qual é (re)elaborada. Não se trata, portanto, ao menos não necessariamente, de nacionalismo, embora tenha sido este o caso, politicamente falando, do próprio Caio Prado.
} 
do capitalismo, e não como apanágio de uma crítica geral e abstrata do sistema. Mais ainda, se Schwarz redobra a aposta adorniana no valor de conhecimento da arte e/ou da literatura, ele assim o faz num país onde essa última significou, por muito tempo, o principal instrumento de revelação da experiência nacional, à diferença, por exemplo, da situação europeia, na qual o ensaísmo de esquerda ancorava-se na presença de uma teoria social avançada. No Brasil, escreve Schwarz: "pobre em reflexão crítica sobre a sociedade, o rendimento extraliterário dessa potência de revelação das formas [a literatura] oferece campo e tem oportunidade excepcional" (Schwarz, 1999a, p. 44). Para Schwarz, não sem certa ironia polêmica: "a boa literatura brasileira é mais adiantada ou mais diferenciada do que os nossos historiadores e sociólogos" (Schwarz, 1999c, p. 232).

Na obra de um autor como Machado de Assis, por exemplo, argumenta ele, a "constelação" resultante da articulação tipicamente brasileira entre herança colonial e racionalidade burguesa apresentar-se-ia de forma muito mais problematizada do que nos esquemas de grandes "cientistas sociais" (no sentido amplo) como Gilberto Freyre e/ ou mesmo Caio Prado Jr., o primeiro assentado na valorização saudosista da molécula patriarcal, o segundo numa perspectiva abstratamente "progressista" do desenvolvimento nacional (Schwarz, 1999c, p. 232-233). O “mix" machadiano, estando além das construções sociológicas correntes, demandaria, conforme afirmou o autor em entrevista de 2008, uma "sociologia nova, para a qual a crítica literária seria um indicador-chave" (Schwarz, 2008, p. 157).

Ora, talvez tenha sido exatamente essa a enorme contribuição de Roberto Schwarz para o (ou para a crítica ao) pensamento sobre o Brasil, a saber: a elaboração desta "sociologia nova", autorreflexiva, pautada pela tentativa de "explicação sociológica de uma evidência estética", mais do que pela elaboração de uma "versão estética [da] teoria sociológica" (cf. 
Schwarz, 1994-1995). Foi por meio desta sociologia "impura" (cf. Cohn, 2008), carregada de percepção literária e de pressupostos crítico-normativos, que Schwarz consolidou seu lugar ímpar no cenário intelectual brasileiro do último quarto do século XX e início do XXI, tornando-se um mestre na arte de pensar o Brasil ao quadrado.

\section{Fabio Mascaro Querido}

é professor do Departamento e do Programa de PósGraduação em Sociologia do Instituto de Filosofia e Ciências Humanas (IFCH) da Unicamp. Autor de Michael Löwy: marxismo e crítica da modernidade (Boitempo, 2016) e (com Arno Münster) Le marxisme " ouvert » et écologique de Michael Löwy (L'Harmattan, 2019). Coordenador do grupo de pesquisa Teoria Crítica e Sociologia (IFCH-Unicamp) e diretor associado do Centro de Estudos Marxistas (IFCHUnicamp). Membro do comitê editorial da coleção Sociologias Contemporâneas (Alameda), do Programa de Pós-Graduação em Sociologia da Unicamp. Foi pesquisador visitante na École des Hautes Études en Sciences Sociales (EHESS, Paris, França) em 2018. Tem experiência nas áreas de Teoria Sociológica, Pensamento Social e Político e Sociologia da Cultura.

\section{Bibliografia}

ADORNO, Theodor. 1982. Teoria Estética. Lisboa: Edições 70.

ADORNO, Theodor. 2003. O ensaio como forma. In: ADORNO, Theodor.

Notas de Literatura I. São Paulo: Duas Cidades: Editora 34. pp. 15-45.

ARANTES, Paulo. 1996. O fio da meada. Rio de Janeiro: Paz e Terra.

ARANTES, Paulo. 2004. A fratura brasileira do mundo. In: ARANTES,

Paulo. Zero à esquerda. São Paulo: Conrad. pp. 25-78.

BLAY, Eva. 2010. Mulheres cientistas: aspectos da vida e obra de Khäte

Schwarz. Estudos feministas, n. 18, pp. 473-489.

BOSI, Alfredo. 2001. Dialética da colonização. São Paulo: Companhia das

Letras. 
BRANDÃO, Gildo. 2007. Linhagens do pensamento político brasileiro. São Paulo: Hucitec.

CANDIDO, Antonio. 1974. Memorial para concurso de professor titular. São Paulo: FFLCH-USP.

CANDIDO, Antonio. 2000. Crítica e sociologia: tentativa de esclarecimento. In: CANDIDO, Antonio. Literatura e sociedade. São Paulo: Publifolha. pp. 5-16.

CANDIDO, Antonio. 2011. Entrevista com Antonio Candido. Trans/form/ ação, v. 34, pp.3-13. Edição especial.

CARDOSO, Fernando Henrique. 1997. Capitalismo e escravidão no Brasil meridional. Rio de Janeiro: Paz e Terra.

COHN, Gabriel. 2008. Apresentação à edição brasileira: a sociologia como ciência impura. In: ADORNO, Theodor. Introdução à sociologia. São Paulo: Editora Unesp. pp. 19-34.

COUTINHO, Carlos Nelson. 2000. Cultura e sociedade no Brasil: ensaios sobre ideias e formas. Rio de Janeiro: DP\&A.

FRANCO, Maria Sylvia de Carvalho. 1970. O moderno e suas diferenças. Tese de Livre-Docência em Ciências Sociais. São Paulo: FFLCH-USP.

FRANCO, Maria Sylvia de Carvalho. 1976. As ideias estão no lugar. Cadernos de debate, n. 1, pp. 61-64.

JACKSON, Luiz Carlos; BLANCO, Alejandro. 2014. Sociologia no espelho: ensaístas, cientistas sociais e críticos literários no Brasil e na Argentina (1930-1970). São Paulo: Editora 34.

JAMESON, Frederic. 1985. Marxismo e forma: teorias dialéticas da literatura no século XX. São Paulo: Hucitec.

KURZ, Robert. 2001. O colapso da modernização: da derrocada do socialismo de caserna à crise da economia mundial. Rio de Janeiro: Paz e Terra.

MICELI, Sergio. 2007. O chão e as nuvens: ensaios de Roberto Schwarz entre arte e ciência. In: CEVASCO, Maria Elisa; OHATA, Milton. Um crítico na periferia do capitalismo: reflexões sobre a obra de Roberto Schwarz. São Paulo: Companhia das Letras. pp. 54-65.

NOVAIS, Fernando. 1983. Portugal e Brasil na crise do antigo sistema colonial. São Paulo: Hucitec.

OLIVEIRA, Francisco de. 2003. Crítica da razão dualista: o ornitorrinco. São Paulo: Boitempo.

ORTIZ, Renato. 1990. Notas sobre as Ciências Sociais no Brasil. Novos Estudos, n. 27, pp. 163-176.

QUERIDO, Fabio Mascaro. 2013. Colapso da modernização: Roberto Schwarz e a atualização da dialética à brasileira. Novos Estudos, n. 97, pp. 227-233. 
RICUPERO, Bernardo. 2000. Caio Prado Jr. e a nacionalização do marxismo no Brasil. São Paulo: Editora 34.

RICUPERO, Bernardo. 2013. O lugar das ideias: Roberto Schwarz e seus críticos. Sociologia $\mathcal{E}^{2}$ Antropologia, v. 3, n. 6, pp. 525-556.

RIDENTI, Marcelo. 2010. Brasilidade revolucionária como estrutura de sentimento. In: RIDENTI, Marcelo. Brasilidade revolucionária: um século de cultura e política. São Paulo: Editora Unesp.

RODRIGUES, Lidiane Soares. 2011. A produção social do marxismo universitário em São Paulo: mestres, discípulos e um seminário (1958-1978).

Tese de Doutorado em História Social. São Paulo: FFLCH-USP.

SCHWARZ, Roberto. 1965. A sereia e o desconfiado: ensaios críticos. São Paulo: Civilização Brasileira.

SCHWARZ, Roberto. 1978. Cultura e política, 1964-1969. In: SCHWARZ, Roberto. O pai de família e outros estudos. Rio de Janeiro: Paz e Terra. pp. 61-92.

SCHWARZ, Roberto. 1981. Amor sem uso. Novos Estudos, n. 1, p. 3.

SCHWARZ, Roberto. 1987a. A carroça, o bonde e o poeta modernista. In: SCHWARZ, Roberto. Que horas são? Ensaios. São Paulo: Companhia das Letras. pp.11-27.

SCHWARZ, Roberto. 1987b. Pressupostos, salvo engano, de 'Dialética da Malandragem'. In: SCHWARZ, Roberto. Que horas são? Ensaios. São Paulo: Companhia das Letras. pp.129-155.

SCHWARZ, Roberto. 1994-1995. Do lado da viravolta: entrevista com Roberto Schwarz. [Entrevista cedida a] Fernando Haddad e Maria Rita Kehl. Teoria e Debate, n. 27.

SCHWARZ, Roberto. 1999a. Adequação nacional e originalidade crítica. In: SCHWARZ, Roberto. Sequencias brasileiras: ensaios. São Paulo: Companhia das Letras. pp. 24-45.

SCHWARZ, Roberto. 1999b. A nota específica. In: SCHWARZ, Roberto. Sequencias brasileiras: ensaios. São Paulo: Companhia das Letras. pp. 151-154.

SCHWARZ, Roberto. 1999c. Conversa sobre "Duas meninas". In: SCHWARZ, Roberto. Sequencias brasileiras: ensaios. São Paulo: Companhia das Letras. pp. 227-238.

SCHWARZ, Roberto. 1999d. Fim de século. In: SCHWARZ, Roberto. Sequencias brasileiras: ensaios. São Paulo: Companhia das Letras. pp. 155-162.

SCHWARZ, Roberto. 1999e. Um seminário de Marx. In: SCHWARZ, Roberto. Sequencias brasileiras: ensaios. São Paulo: Companhia das Letras. pp. 86-105. 
SCHWARZ, Roberto. 2000a. Ao vencedor as batatas. São Paulo: Duas cidades: Editora 34.

SCHWARZ, Roberto. 2000b. Um mestre na periferia do capitalismo: Machado de Assis. São Paulo: Duas Cidades: Editora 34..

SCHWARZ, Roberto. 2006. Leituras em competição. Novos Estudos, n. 75, pp.61-79.

SCHWARZ, Roberto. 2008. Ao vencedor as batatas 30 anos: crítica da cultura e processo social. [Entrevista cedida] a André Botelho e Lília Schwarcz. Revista Brasileira de Ciências Sociais, n. 67, pp. 147-194.

SCHWARZ, Roberto. 2009. Entrevista. In: MONTERO, Paula; MOURA, Flávio (org.). Retrato de grupo: 40 anos do Cebrap. São Paulo: Cosac Naify.

SCHWARZ, Roberto. 2012a. Por que "ideias fora do lugar"?. In:

SCHWARZ, Roberto. Martinha versus Lucrécia: ensaios e entrevistas. São Paulo: Companhia das Letras. pp. 165-172.

SCHWARZ, Roberto. 2012b. Verdade tropical: um percurso de nosso tempo. In: SCHWARZ, Roberto. Martinha versus Lucrécia: ensaios e entrevistas. São Paulo: Companhia das Letras. pp. 52-110.

WAIZBORT, Leopoldo. 2007. A passagem do três ao um: crítica literária, sociologia, filologia. São Paulo: Cosac Naify. 


\section{PENSAMENTO AO QUADRADO: ROBERTO SCHWARZ E 0 BRASIL}

\section{FABIO MASCARO QUERIDO}

Resumo: O objetivo deste artigo é analisar a obra (e a trajetória) de Schwarz do ponto de vista da sua abordagem - em suas continuidades e descontinuidades - dos desafios e impasses do pensamento social brasileiro, o qual estaria circunscrito, mesmo nas suas vertentes mais avançadas, como aquela oriunda do "Seminário d'O Capital', ao horizonte modernizador e industrializante à luz do qual foram pensadas as soluções ao problema da má-formação nacional. Atina-se com a hipótese de que foi a transição precoce das ciências sociais para a crítica literária/cultural, sem renegar a primeira, bem ao contrário, que permitiu a Schwarz forjar uma visão singular da sociedade brasileira, sociedade esta pensada ao quadrado, à maneira adorniana, isto é, divisada através da análise crítica da experiência intelectual e/ou artística da época.

Palavras-chave: Roberto Schwarz; Crítica Literária; Pensamento Social Brasileiro; Teoria Crítica.

\section{SQUARED THOUGHT: ROBERTO SCHWARZ AND BRAZIL}

Abstract:The aim of this article is to analyze the work of Schwarz from the point of view of his approach - in its continuities and discontinuities - on the challenges and dilemmas of Brazilian social thought, which would be restricted, even in their most advanced aspects, as the one from the "Seminar of The Capital", to the horizon of the modernization. It is assumed that it was the early transition of social sciences to literary/cultural critique which allowed Schwarz to build a particular view of the Brazilian society, society squared thought, that is, a view through a critical analysis of the intellectual/ artistic experience of the time.

Keywords: Roberto Schwarz; Literary Critique; Brazilian Social Thought; Critical Theory.

Recebido: 26/04/2017 Aprovado: 18/07/2019 